\title{
Physical behaviors of 12-15 year-old adolescents in 54 low- and middle-income countries: Results from the Global School-based Student Health Survey
}

\author{
Guodong $\mathrm{Xu}^{1,2,3 *}$, Ning Sun ${ }^{4 *}$, \\ Lian $\mathrm{Li}^{5}$, Wanfu $\mathrm{Qi}^{6}$, Changwei $\mathrm{Li}^{7}$, \\ Maigeng Zhou ${ }^{8}$, Zhu Chen ${ }^{1 \dagger}$, Liyuan \\ $\operatorname{Han}^{1,2 \dagger}$ \\ ${ }^{1}$ Hwa Mei Hospital, University of Chinese \\ Academy of Sciences, Ningbo, Zhejiang, PR \\ China \\ ${ }^{2}$ Ningbo Institute of Life and Health Industry, \\ University of Chinese Academy of Sciences, \\ Ningbo, Zhejiang, PR China \\ ${ }^{3}$ Ningbo Medical Center Lihuili Hospital, Ning- \\ bo, Zhejiang, PR China \\ ${ }^{4}$ Ningbo College of Health Sciences, Ningbo, \\ Zhejiang, PR China \\ ${ }^{5}$ Zhejiang Provincial Key Laboratory of Patho- \\ physiology, School of Medicine, Ningbo \\ University, Ningbo, PR China \\ ${ }^{6}$ Ningbo Health Supervision Institute, Ningbo, \\ Zhejiang, PR China \\ ${ }^{7}$ Department of Epidemiology and Biostatis- \\ tics, University of Georgia College of Public \\ Health, Athens, Georgia, USA \\ ${ }^{8}$ National Center for Chronic and Noncom- \\ municable Disease Control and Prevention, \\ Chinese Center for Disease Control and \\ Prevention, Beijing, PR China \\ *Equal first authorship. \\ $\dagger$ Equal senior authorship.
}

\section{Correspondence to:}

Zhu Chen, PhD

HwaMei Hospital

University of Chinese Academy of Sciences Ningbo

Zhejiang, 315000

China

mars853234@163.com

\section{Liyuan Han, PhD}

HwaMei Hospital

University of Chinese Academy of Sciences

Ningbo

Zhejiang, 315000

China

hanliyuan@nbu.edu.cn
Background To describe and compare the separate and combined prevalence of physical activity, active transportation, physical education, and sedentary behavior among adolescents $12-15$ year-olds in low- and middle-income countries (LMICs).

Methods We used the latest data from the Global School-based Student Health Survey (GSHS), which collect data on the physical behaviors of young adolescents in LMICs. The weighted prevalence and 95\% confidence intervals of separate, combined and all of the qualifying physical behaviors were calculated. Pooled overall and regional estimates were calculated using a random effects model.

Results In total, 154559 young adolescents (45.90\% boys) aged 12-15 from 54 countries covered in the GSHS were included in our analysis. Only $0.7 \%$ (95\% confidence interval $(\mathrm{CI})=0.5 \%-1.0 \%)$ of the adolescents, comprising $0.9 \%$ ( $95 \% \mathrm{CI}=0.6 \%-1.3 \%$ ) of the boys and $0.5 \%(95 \% \mathrm{CI}=0.3 \%-0.7 \%)$ of the girls, displayed all of the qualifying physical behaviors. The overall prevalence of physical activity, active transportation, physical education, and sedentary behavior was $15.2 \%$ (95\% CI $=13.7 \%-16.7 \%$ ), 39.5\% (95\% CI $=34.9 \%-44.0 \%$ ), $18.8 \%$ (95\% $\mathrm{CI}=16.1 \%-21.5 \%$ ), and $34.6 \%$ (95\% CI $=28.4 \%-40.7 \%)$, respectively. The overall prevalence of high levels of combined physical behaviors was $6.6 \%$ (95\% CI=5.4\%-7.8\%), with lowest in the Eastern Mediterranean region $(4.9 \%, 95 \% \mathrm{CI}=3.5 \%-6.2 \%)$ and highest in Southeast Asia (8.6\%, 95\% CI $=4.9 \%-12.3 \%)$.

Conclusion The prevalence of the separate physical behaviors and high levels of the combined physical behaviors was consistently low among young adolescents in LMICs, and that of all qualifying physical behaviors was even lower.

Globally, physical inactivity and sedentary behavior are highly prevalent in adolescents [1]. Reportedly, only approximately $23.8 \%$ of boys and $15.4 \%$ of girls engage in at least 60-minute of physical activity per day [2]. In addition, more than half of the adolescents sit for $>3$ hours per day outside school [3].

Accumulating evidence has suggested that physical activity has protective effects against cardiovascular diseases [4], diabetes [5], and cancer [6], whereas sedentary behavior increases the risk of obesity and cardiometabolic diseases $[7,8]$. However, the risk attributable to sedentary behavior depends on the amount of moderate-to-vigorous physical activity $[9,10]$. 
More than 1 hour of moderate-intensity physical activity can eliminate the increased risk of death associated with a long sitting time [11]. However, if the sitting time is more than 5 hours per day, mortality significantly increases regardless of the intensity of physical activity [11].

Notably, engaging in active transportation and attending physical education increase the chances of meeting physical activity recommendations among adolescents [12,13]. Active commuting to and from school can help in increasing daily physical active levels in youth [14], and approximately $50 \%$ of physical education lesson time is spent on physical activity [15]. Taken together, these findings suggest that physical activity, active transportation, physical education, and sedentary behavior together influence adolescent health.

A study described worldwide physical activity levels, showing $80 \%$ of adolescents do not reach recommended levels of physical activity, and more than $65 \%$ spend 2 hours or more per day watching television from the data of 41 countries in Europe and North America [1]. However, most studies have focused the prevalence of physical activity, active transportation, physical education, and sedentary behavior in adolescents separately [3]. To date, no study has estimated the combined prevalence of the four above mentioned physical behaviors in young adolescents in low- and middle-income countries (LMICs). Therefore, using the most current GSHS data sets of 2009-2015, we described the separate and combined prevalence of physical activity, active transportation, physical education, and sedentary behavior, as well as all qualifying physical behaviors, in 12-15 year-old adolescents in 54 LMICs and examined the differences between subgroups stratified by gender, age, and body mass index (BMI).

\section{MATERIALS AND METHODS}

\section{Data sources}

The detailed methods used in the GSHS have been described online on the World Health Organization (WHO) website (http://www.who.int/ncds/surveillance/gshs/en/), on the Centers for Disease Control and Prevention (CDC) website (https://www.cdc.gov/gshs/index.htm), and in previous reports [16,17]. The GSHS is a multicenter, multiethnic, school-based, and ongoing collaborative surveillance project led by WHO and the United States CDC, mainly conducted to assess health behaviors and protective factors among 12-15 year-old adolescents. The GSHS uses a self-administered questionnaire to obtain data on adolescent health behaviors and protective factors in 10 key areas, namely alcohol use, dietary behaviors, drug use, hygiene, mental health, physical activity, protective factors, sexual behaviors, tobacco use, and violence and unintentional injury. The data are collected during regular school hours using a self-report computer-scannable form. The questionnaire is translated into the appropriate language for each country, if necessary. All responses are anonymous, and no identifiable information is collected. Countries can select the sections of the questionnaire they wish to use. However, the questions within the chosen survey sections must be used without modification, so the results are directly comparable across countries and over repeat assessments $[16,17]$.

A standardized two-stage random cluster sampling procedure was used to select eligible participants from each country [18]. Approval for the GSHS was obtained from the local national government administrations of all countries. Participation by adolescents in all countries was voluntary, and written consent was obtained from them or their parents.

Definitions of physical activity, active transportation, physical education, and sedentary behavior

For physical activity, the form included the following question: "During the past 7 days, on how many days were you physically active for a total of at least 60 min per day?" The response options were " 0 days," "1 day," "2 days," "3 days," "4 days," "5 days," " 6 days," or "7 days." Adolescents who were physically active for at least 1 hour per day were considered to engage in "physical activity" [3].

For active transportation, the form included the following question: "During the last 7 days, on how many days did you walk or ride a bicycle to or from school?" The response options were the same as above. Adolescents who walked or rode a bicycle to or from school for at least 3 days per week were considered to engage in "active transportation" [3].

For physical education, the form included the following question: "During this school year, on how many days did you go to a physical education class each week?" The response options were " 0 days," "1 day," "2 days," "3 days," "4 days," or " 5 or more days." Adolescents who went to physical education class at least 5 days per week were considered to attend "physical education" [3]. 
For sedentary behavior, the form included the following question: "How much time do you spend during a typical or usual day sitting and watching television, playing computer games, talking with friends, or doing other seated activities such as surfing the Internet?" The response options were "less than $1 \mathrm{~h}$ per day," "1 to 2 h per day," "3 to 4 h per day," "5 to 6 h per day," "7 to 8 h per day," or "more than 8 h per day." Adolescents who spent 3 or more hours per day sitting down were classified as having "sedentary behavior" [3].

\section{All qualifying and combined physical behaviors}

Adolescents who were physically active, engaged in active transportation, attended physical education classes, and had no sedentary behavior were classified as having all qualifying physical behaviors.

For physical activity and active transportation in the past 7 days, we assigned scores from 0 to 7 for 0 to 7 days, respectively. For physical education in the past 7 days, we assigned scores from 0 to 4 for 0 to 4 days, respectively, and 5 for " 5 or more days." For sedentary behavior, we assigned scores of 5 for "less than 1 h per day," 4 for " 1 to 2 h per day," 3 for " 3 to 4 h per day," 2 for " 5 to 6 h per day," 1 for " 7 to 8 h per day," and 0 for "more than 8 h per day."

The combined physical behaviors of the young adolescents were calculated by summing the scores of the four above mentioned survey items, with the highest possible scores being 24. A higher score indicated better physical behavior. In addition, the combined physical behaviors of young adolescents were grouped into the following quartiles: low (score 0-6), moderately low (score 7-12), moderately high (score 13-18), or high (score 19-24).

\section{Statistical analysis}

As the GSHS uses a complex sampling design, data analyses should take into account sampling design. The prevalence of physical activity, active transportation, physical education, and sedentary behavior separately, as well as the prevalence of combined physical behaviors, was reported as weighted prevalence values and 95\% confidence intervals (CIs) using the SAS SURVEYMEANS procedure. This procedure produces survey population estimates, such as proportions and $95 \%$ confidence intervals (CI), from sample survey data while accounting for the sample design used to select the survey sample. In our analyses, we added weights, stratum, and a primary sampling unit (PSU) to every student record in the GSHS data file to reflect the weighting process and the two-stage sampling design. The weights allow the results to be generalized to the study population and the national student population. The stratum reflects the first stage of the GSHS sampling (school level), and the PSU reflects the second stage (classroom level).

Pooled overall and regional estimates were calculated by meta-analysis using the random-effects model. Heterogeneity was assessed using the $I^{2}$ statistic. Subgroup analyses were stratified by gender (boys vs girls), age (12-13 years vs 14-15 years), and BMI (normal, overweight, and obesity). The differences in prevalence between gender, age, and BMI groups were estimated using the $\chi^{2}$ test. Standard errors were estimated using the Taylor series linearization method [19]. $P$ values $<0.05$ were considered to indicate statistically significant differences.

BMI was calculated as kilograms per square meter $\left(\mathrm{kg} / \mathrm{m}^{2}\right)$. The BMI of adolescents was categorized as underweight $\left(<5^{\text {th }}\right.$ percentile), normal ( $5^{\text {th }}$ to $<85^{\text {th }}$ percentiles), overweight $(85$ th to $<95$ th percentiles), and obese ( $\geq 95^{\text {th }}$ percentile) based on their age and gender [20]. SAS version 9.4 (SAS Institute, Cary, NC) and STATA version 12.0 (Stata Corporation; College Station, TX, USA) were used to perform statistical analyses.

\section{RESULTS}

Table 1 summarizes the characteristics of the survey and participants from the GSHS. A total of 154559 adolescents (45.90\% of whom were boys) aged 12-15 years with complete data on physical activity, active transportation, physical education, and sedentary behavior between 2009 and 2015 were included in our study. Fifty-four countries from five WHO regions (8 from Africa, 17 from America, 12 from Eastern Mediterranean, 4 from Southeast Asia, and 13 from Western Pacific) were included (Figure 1). Sample sizes ranged from 697 in Mozambique (the Africa region) to 21762 in Argentina (the America region). The overall response rate was $98.56 \%$ (95\% CI=88.39\%-99.83\%). 
Table 1. Survey characteristics of the Global School-based Student Health Surveys according to country, 2009-2015

\begin{tabular}{|c|c|c|c|c|}
\hline & SURVEY YEAR & Response rate $(\%)$ & SAMPLE SIZE & Boys (\%) \\
\hline \multicolumn{5}{|l|}{ Africa Region: } \\
\hline Algeria & 2011 & 99.01 & 3527 & 45.51 \\
\hline Benin & 2009 & 99.58 & 1179 & 63.60 \\
\hline Mauritania & 2010 & 95.68 & 1320 & 45.8 \\
\hline Mauritius & 2011 & 98.03 & 2081 & 45.68 \\
\hline Mozambique & 2015 & 97.42 & 697 & 50.24 \\
\hline Namibia & 2013 & 97.98 & 1981 & 41.51 \\
\hline Seychelles & 2015 & 94.47 & 2063 & 44.84 \\
\hline United Republic of Tanzania & 2014 & 96.97 & 2643 & 44.68 \\
\hline \multicolumn{5}{|l|}{ Region of the Americas: } \\
\hline Antigua and Barbuda & 2009 & 94.05 & 1243 & 46.39 \\
\hline Argentina & 2012 & 96.29 & 21762 & 46.38 \\
\hline Barbados & 2011 & 97.88 & 1507 & 45.11 \\
\hline Belize & 2009 & 97.10 & 1621 & 46.64 \\
\hline Bolivia & 2012 & 98.11 & 2956 & 49.76 \\
\hline Chile & 2013 & 96.23 & 1354 & 48.43 \\
\hline Bahamas & 2013 & 94.74 & 1312 & 44.99 \\
\hline Costa Rica & 2009 & 99.25 & 2277 & 47.58 \\
\hline Curaçao & 2015 & 92.51 & 1508 & 45.67 \\
\hline El Salvador & 2013 & 98.42 & 1644 & 52.72 \\
\hline Guatemala & 2015 & 93.02 & 3666 & 47.33 \\
\hline Guyana & 2010 & 98.19 & 1985 & 43.61 \\
\hline Honduras & 2012 & 97.60 & 1502 & 47.30 \\
\hline Peru & 2010 & 99.83 & 2374 & 48.51 \\
\hline Suriname & 2009 & 96.89 & 1062 & 46.17 \\
\hline Trinidad and Tobago & 2011 & 95.76 & 2383 & 54.39 \\
\hline Uruguay & 2012 & 98.28 & 2905 & 46.56 \\
\hline \multicolumn{5}{|l|}{ Eastern Mediterranean Region: } \\
\hline Afghanistan & 2014 & 96.14 & 1530 & 37.31 \\
\hline Egypt & 2011 & 98.56 & 2424 & 45.65 \\
\hline Iraq & 2012 & 95.81 & 1553 & 54.79 \\
\hline Kuwait & 2015 & 91.77 & 2066 & 46.78 \\
\hline Lebanon & 2011 & 95.79 & 1995 & 46.93 \\
\hline Morocco & 2010 & 98.98 & 2451 & 50.15 \\
\hline Oman & 2015 & 99.29 & 1681 & 43.54 \\
\hline Pakistan & 2009 & 99.10 & 5005 & 74.80 \\
\hline Qatar & 2011 & 90.18 & 1802 & 44.41 \\
\hline Sudan & 2012 & 96.41 & 1476 & 35.87 \\
\hline Syrian Arab Republic & 2010 & 99.29 & 2941 & 40.04 \\
\hline United Arab Emirates & 2010 & 96.20 & 2313 & 38.28 \\
\hline \multicolumn{5}{|l|}{ Southeast Asia Region: } \\
\hline Bangladesh & 2014 & 96.49 & 2760 & 38.48 \\
\hline Indonesia & 2015 & 98.02 & 8824 & 46.37 \\
\hline Thailand & 2015 & 97.78 & 4149 & 46.56 \\
\hline Timor-Leste & 2015 & 98.48 & 1705 & 41.67 \\
\hline \multicolumn{5}{|l|}{ Western Pacific Region: } \\
\hline Brunei Darussalam & 2014 & 98.41 & 1827 & 46.05 \\
\hline Cambodia & 2013 & 98.90 & 1820 & 43.76 \\
\hline Kiribati & 2011 & 99.12 & 1358 & 41.29 \\
\hline Lao People's Democratic Republic & 2015 & 99.82 & 1664 & 41.98 \\
\hline Malaysia & 2012 & 99.61 & 16287 & 51.15 \\
\hline Mongolia & 2013 & 99.54 & 3720 & 47.62 \\
\hline Philippines & 2015 & 98.95 & 6167 & 43.37 \\
\hline Samoa & 2011 & 88.39 & 2213 & 39.52 \\
\hline Solomon Islands & 2011 & 97.65 & 979 & 50.11 \\
\hline Tonga & 2010 & 99.13 & 1958 & 44.58 \\
\hline Vanuatu & 2011 & 99.31 & 865 & 40.81 \\
\hline Vietnam & 2013 & 99.60 & 1749 & 46.79 \\
\hline Wallis and Futuna & 2015 & 92.83 & 725 & 48.28 \\
\hline Total & & 98.56 & 154559 & 45.90 \\
\hline
\end{tabular}




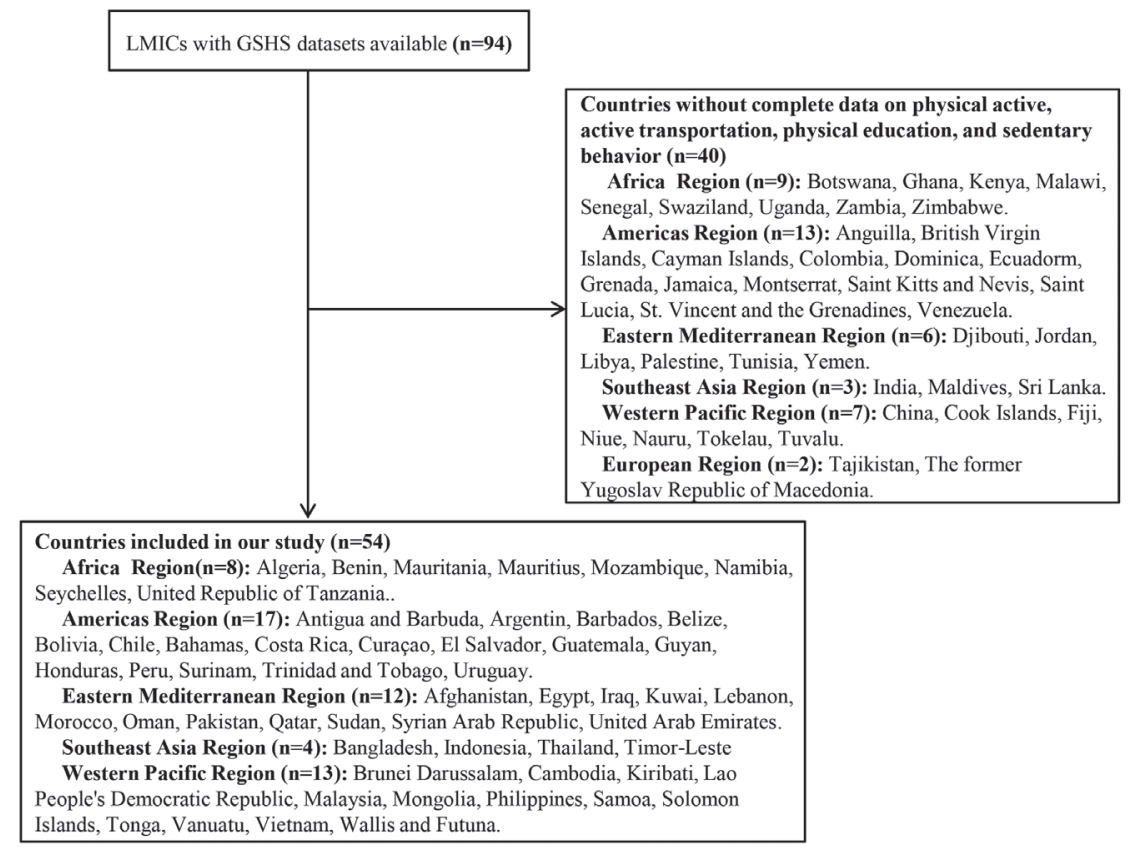

Figure 1. Selection process for low- and middle-income countries (LMICs) using the Global School-based Student Health Survey (GSHS) national data.

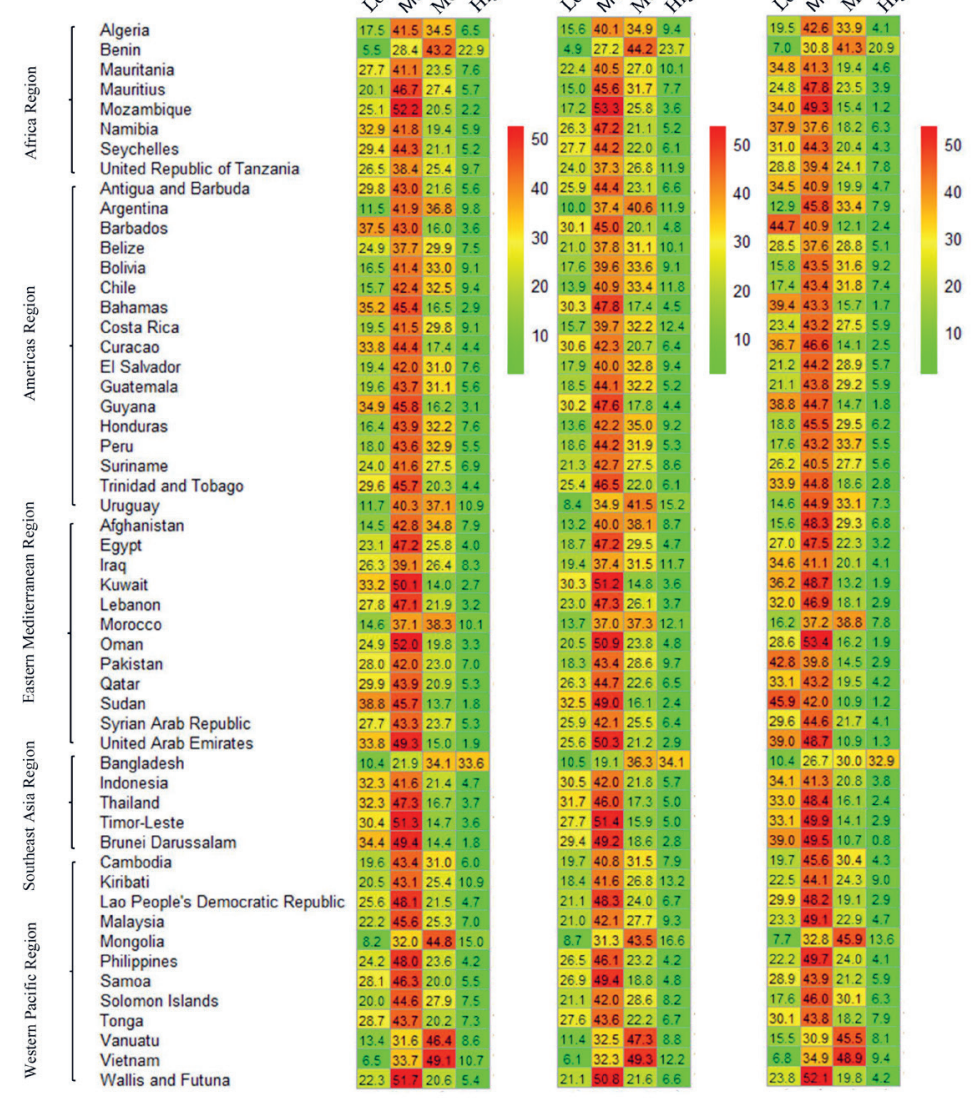

Figure 2. Combined physical behaviors in adolescents aged $12-15$ years by gender and country group.
The overall prevalence of low (0-6), moderately low (7-12), and moderately high levels of combined physical behaviors across the 54 countries was $24.1 \%$ (95\% CI $=21.6 \%-26.5 \%), 43.0 \%$ (95\% $\mathrm{CI}=42.1 \%-43.9 \%)$, and $25.3 \%$ (95\% CI $=22.8 \%$ $27.7 \%$ ), respectively (Figure 2 and Table S1 in the Online Supplementary Document). The overall prevalence of high levels (score 19-24) of combined physical behaviors was 6.6\% (95\% $\mathrm{CI}=5.4 \%-7.8 \%$ ), with the lowest in Sudan and Brunei Darussalam (1.8\%, 95\% CI=0.9\%-2.7\%) and $1.8 \%, 95 \% \mathrm{CI}=1.1 \%-2.4 \%)$ and the highest in Bangladesh (33.6\%, 95\% CI =27.2\%-40.0\%) (Figure 2 and Table S1 in the Online Supplementary Document).

The pooled prevalence of high levels of combined physical behaviors was the lowest in the Eastern Mediterranean (4.9\%. 95\% CI=3.5\%$6.2 \%$ ) and the highest in Southeast Asia (8.6\%, 95\% CI $=4.9 \%-12.3 \%$ ) (Figure 3 and Table S1 in the Online Supplementary Document). The prevalence of high levels of combined physical behaviors was $7.8 \%$ (6.5\%-9.0\%) in boys and $>5.1 \%$ (3.8\%-6.4\%) in girls ( $P=0.02$, Table S1 in the Online Supplementary Document). No statistical significances were observed between different age or BMI groups (Table S2 and S3 in the Online Supplementary Document, respectively).

The prevalence of physical activity among young adolescents across the 54 countries was $15.2 \%$ (13.7\%-16.7\%), with the lowest in Cambodia $(6.3 \%, 95 \% \mathrm{CI}=4.5 \%-8.2 \%)$ and the highest in 


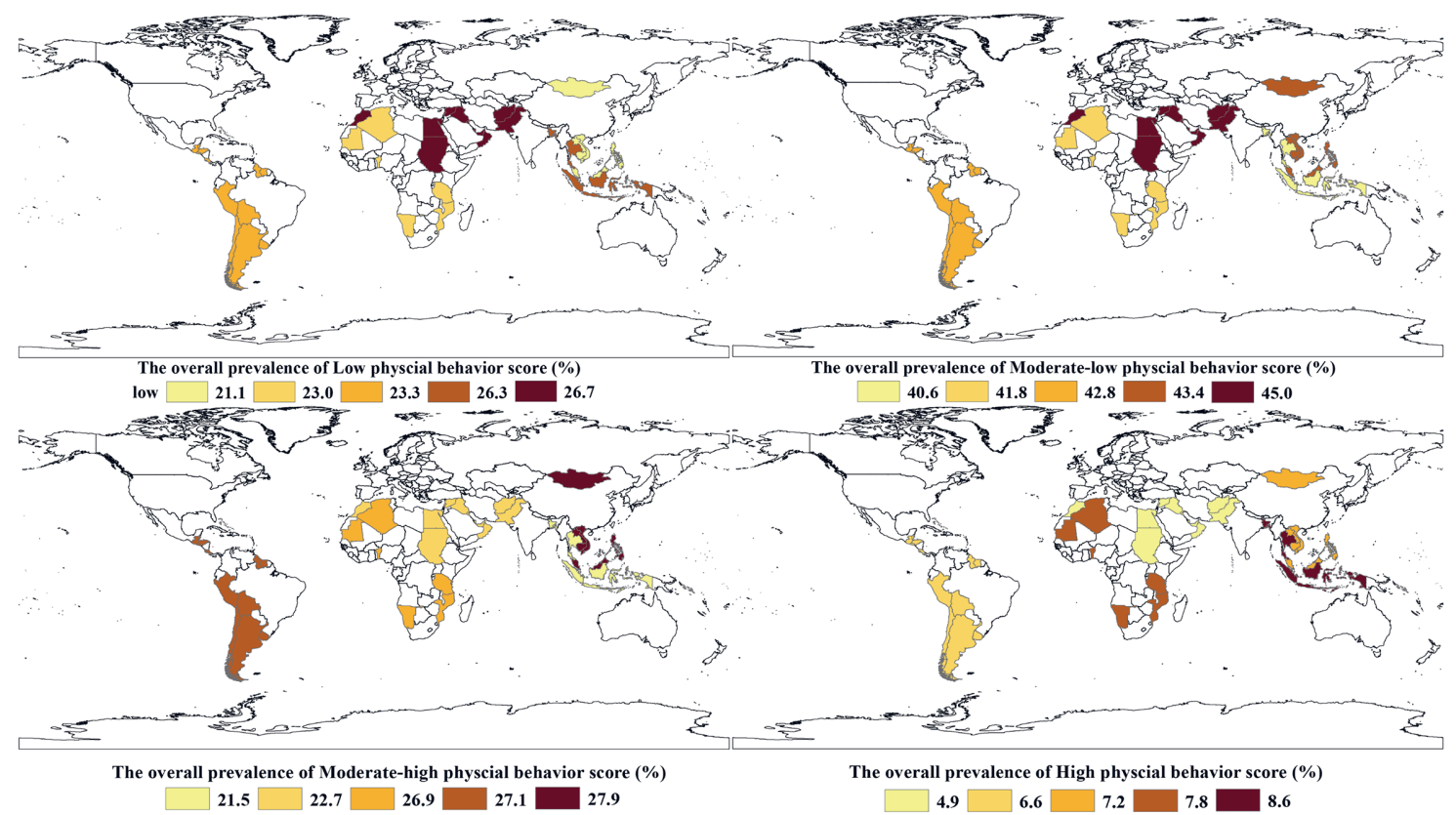

Figure 3. Pooled estimates of combined physical behaviors among adolescents aged 12-15 years by WHO region, 2009-2015

Bangladesh (42.2\%, 95\% CI=37.0\%-47.4\%) (Table S4 in the Online Supplementary Document). Its pooled prevalence was the lowest in the Eastern Mediterranean $(13.4 \%, 95 \% \mathrm{CI}=11.1 \%-15.6 \%)$ and the highest in Southeast Asia (18.0\%, 95\% CI=10.8\%-25.1\%) (Figure 4 and Table S4 in the Online Supplementary Document). In 40 of the 54 countries (74.1\%), the prevalence of physical activity was higher among boys than among girls (all $P<0.05$ ), and the pooled prevalence was also higher among boys than among girls (18.7\%, 95\% CI =16.6\%-20.9\%, vs $11.7 \%, 95 \% \mathrm{CI}=10.8 \%-12.7 \% ; P=0.02$ ).

The prevalence of engaging in active transportation among young adolescents across the 54 countries was 39.5\% (34.9\%-44.0\%), with the lowest in the United Arab Emirates (10.4\%, 95\% CI =7.3\%-13.5\%) and the highest in Vietnam (78.8\%, 95\% CI=74.5\%-82.8\%) (Table S5 in the Online Supplementary Document). Its pooled prevalence was the lowest in the Eastern Mediterranean (34.2\%, 95\% CI = 24.4\%44.0\%) and the highest in the Western Pacific (44.1\% (33.9\%-54.2\%) (Figure 4 and Table S5 in the Online Supplementary Document). In 20 of the 54 countries, the prevalence of engaging in active transportation was higher in boys than in girls (Table S5 in the Online Supplementary Document).

The prevalence of attending physical education classes among young adolescents across the 54 countries was $18.8 \%(16.1 \%-21.5 \%)$, with the lowest in Peru $(1.7 \%, 95 \% \mathrm{CI}=0 \%-3.4)$ and the highest in Oman (42.7\%, 95\% CI=39.4\%-46.1\%) (Table S6 in the Online Supplementary Document). Its pooled prevalence was the lowest in Southeast Asia $(15.2 \%, 95 \% \mathrm{CI}=8.8 \%-21.5 \%)$ and the highest in America $(22.4 \%, 95 \% \mathrm{CI}=17.7 \%-27.1 \%)$ (Figure 4 and Table $\mathrm{S} 6$ in the Online Supplementary Document). In 15 of the 54 countries, boys and 14-15-year-old adolescents spent more time on physical education than girls and 12-13-year-old adolescents ( $P=0.01$ and 0.02 , respectively) (Table S6 in the Online Supplementary Document).

The prevalence of sedentary behavior among young adolescents across the 54 countries was 34.6\% (28.4\%-40.7\%), with the lowest in Pakistan (8.3\%, 95\% CI=6.6\%-9.9\%) and the highest in Barbados $(65.2 \%, 95 \%$ CI $=62.1 \%-68.3 \%)$ (Table S7 in the Online Supplementary Document). Its pooled prevalence was the lowest in Southeast Asia (26.4\%, 95\% CI=11.5\%-41.4\%) and the highest in America (43.4\%, 95\% CI=37.3\%-49.5\%) (Figure 4 and Table S7 in the Online Supplementary Document). In 20 of the 54 countries, the prevalence of sedentary behavior was higher in 14-15-year-old adolescents than in younger adolescents (Table S7 in the Online Supplementary Document). The pooled prevalence of sedentary behavior was also higher in 14-15-year-old adolescents than in 12-13-year-old adolescents (36.5\%, 95\% CI $=30.0 \%-43.0 \%$, vs $31.3 \%, 95 \% \mathrm{CI}=25.5 \%-37.7 \% ; P=0.01$ ).

Only $0.7 \%$ (95\% CI $=0.5 \%-1.0 \%)$ of young adolescents across the 54 countries displayed all qualifying physical behaviors, with the lowest in Cambodia $(0.02 \%, 95 \% \mathrm{CI}=0.0 \%-0.1 \%)$ and the highest in Uru- 


\begin{tabular}{|c|c|c|c|c|}
\hline \multicolumn{3}{|l|}{ (A) Physcial active } & \multicolumn{2}{|l|}{ (B) Active transportation } \\
\hline WHO Region & & Prevalence $(95 \% \mathrm{Cl})$ & WHO Region & Prevalence $(95 \% \mathrm{Cl})$ \\
\hline Africa & $\rightarrow$ & $16.6(13.9,19.3)$ & Africa & $41.3(28.5,54.1)$ \\
\hline America & $\vec{i}$ & $16.2(14.2,18.0)$ & America & $40.4(32.9,47.8)$ \\
\hline Eastern Mediterranean & $\rightarrow$ & $13.4(11.1,15.6)$ & Eastern Mediterranean & $34.2(24.4,44.0)$ \\
\hline Southeast Asia & \begin{tabular}{l}
- \\
\hdashline
\end{tabular} & $18.0(10.8,25.1)$ & Southeast Asia & $35.4(19.7,51.0)$ \\
\hline Western Pacific & + & $13.8(10.7,16.9)$ & Western Pacific & $-44.1(33.9,54.2)$ \\
\hline Overall (I-squared $=32.5 \%, p=0.205$ ) & $\theta$ & $15.2(13.7,16.7)$ & Overall $(1-$ squared $=0.0 \%, p=0.679)$ & $39.5(35.0,44.1)$ \\
\hline \multicolumn{3}{|l|}{ (C) Physical education } & \multicolumn{2}{|l|}{ (D) Sedentary behavior } \\
\hline \multicolumn{2}{|l|}{ WHO Region } & Prevalence $(95 \% \mathrm{Cl})$ & WHO Region & Prevalence $(95 \% \mathrm{Cl})$ \\
\hline Africa & + & $20.1(16.8,23.3)$ & Africa & $33.6(25.6,41.7)$ \\
\hline America & $\rightarrow$ & $22.4(17.7,27.1)$ & America & $\rightarrow-43.4(37.3,49.5)$ \\
\hline Eastern Mediterranean & - & $20.2(14.2,26.2)$ & Eastern Mediterranean & $33.6(23.3,43.9)$ \\
\hline Southeast Asia & $\rightarrow$ & $15.2(8.8,21.5)$ & Southeast Asia & $26.4(11.5,41.4)$ \\
\hline Western Pacific & $\rightarrow$ & $15.5(11.6,19.4)$ & Western Pacific & $30.2(22.6,37.9)$ \\
\hline Overall (l-squared $=43.3 \%, p=0.133$ ) & $\hat{\imath}$ & $18.8(16.1,21.5)$ & Overall (I-squared $=60.0 \%, p=0.041)$ & $34.6(28.4,40.7)$ \\
\hline
\end{tabular}

Figure 4. Pooled estimates of percentage of physical active, active transportation, physical education, and sedentary behavior among adolescents aged 12-15 years by WHO region, 2009-2015.

guay $(2.4 \%, 95 \% \mathrm{CI}=1.6 \%-3.2 \%)$ (Table S8 in the Online Supplementary Document). The pooled prevalence was the lowest in Southeast Asia $(0.4 \%, 95 \% \mathrm{CI}=0.2 \%-0.7 \%)$ and the highest in America ( $1.1 \%, 95 \% \mathrm{CI}=0.8 \%-1.4 \%)$ (Table S8 in the Online Supplementary Document). The pooled prevalence was higher among boys than among girls $(0.9 \%, 95 \% \mathrm{CI}=0.6 \%-1.3 \%$, vs $0.5 \%, 95 \% \mathrm{CI}=0.3 \%$ $0.7 \% ; P=0.03$.

\section{DISCUSSION}

Our survey summarized the latest GSHS data (from 2009 to 2015) on physical activity, active transportation, physical education, and sedentary behavior among 12-15 year-old adolescents in 54 LMICs. The prevalence of separate and high levels of combined physical behaviors was consistently low among young adolescents in LMICs, and that of all of the qualifying physical behaviors was even lower. The same questions for the assessment of physical activity were taken in 41 Europe and North America countries, and the results from 2005/2006 survey also showed the low prevalence of sufficient physical activity (25\% and $15 \%$ in 13-year-olds boys and girls, respectively) [21].

The overall prevalence of high levels of combined physical behaviors was the lowest in the Eastern Mediterranean. To date, few countries in the Eastern Mediterranean have commenced any comprehensive strategies for increasing the physical activity levels through sports, recreation, cycling, or walking in young adolescents [22]. In addition, the prevalence of engaging in active transportation was also the lowest in the Eastern Mediterranean. Because of cultural attitudes and beliefs, it is usually perceived that the pursuit of academic excellence has greater status than being physically active in this region [23]. The highest prevalence of high levels of combined physical behaviors was found in the Southeast Asia region, which included only four countries, largely contributed by the highest level of physical activity observed in Bangladesh (42.2\%). Bangladesh is known as one of the poorest nations [24], and 80\% of Bangladeshis live in rural areas. Here, adolescents are exceptionally active because most Bangladeshis earn a living through physical labor and many children help their parents with farm activities.

Another interesting finding of this study was the relationship between physical education and physical activity. School physical education is the only course that ensures all students participate in and increase physical activity. However, physical education is not included in the core curriculum in most countries [25]. Accumulating evidence has indicated that physical education is the most effective approach in maintaining a high level of physical activity in children and adolescents, as well as improving their motor skills, developing a positive disposition for an active lifestyle, and increasing direct engagement in 
moderate-to-vigorous physical activity [26-28]. In particular, Southeast Asia showed the lowest prevalence of physical education and the highest prevalence of physical activity. The Directorate of Technical Education Official states the reasons of low physical education in Asia as a lack of physical facilities, low motivation for physical education, and the lack of mandatory physical education [29]. In addition, the highest prevalence of physical education in the US may be because this region shows the highest prevalence of sedentary behavior (43.4\%).

The physical activity level of girls differs significantly from that of boys, and the disparity is maintained into adulthood [30]. A meta-analysis of 26 prospective cohorts indicated a greater rate of decline in physical activity levels among girls than among boys [30]. In 2012, the data on children and adolescents in 105 countries reported by the Lancet physical activity research working group showed that the deficiency in physical activity increased with age, especially in girls [1]. Similar findings were observed in our study, wherein the pooled prevalence of physical activity was higher among boys than among girls (18.7\%, 95\% $\mathrm{CI}=16.6 \%-20.9 \%$, vs $11.7 \%, 95 \% \mathrm{CI}=10.8 \%-12.7 \%)$. Studies have found that biological factors, lack of enjoyment, and watching the latest variety shows increase the tendency for physical inactivity and sedentary behavior in girls [31,32]. In addition, girls are often overly protected and not encouraged to engage in physical activity by their families [33]. Moreover, compared with boys, girls have limited opportunities and facilities for physical activity [33]. Therefore, adolescent girls may need additional support and encouragement to maintain health-enhancing physical activity.

National or regional physical activity guidelines are regarded by WHO as the most basic steps to promote physical health [1], but at present, such guidelines for adolescents are absent or inadequate in most countries, especially in LMICs. Therefore, on the basis of WHO recommendations, different countries or regions should formulate physical activity guidelines in accordance with their social, cultural, and economic backgrounds to better promote adolescent health in their countries or regions [1]. Multi-component school-based interventions can increase physical activity among youth, such as providing enhanced PE; classroom activity breaks; and after-school activity space and equipment, encourage active transportation to school, and help adolescent building behavioral skills [34].

We used the most recent national GSHS data from 2009 to 2015, and the overall response rate was more than $98.56 \%$. In addition, the use of a large sample size, standard procedures for the selection of participants, direct comparisons, and robust statistical methods to assess estimates of prevalence rates ensured that our findings were reliable and representative. Most previous studies have focused only on physical activity and have barely investigated sedentary behavior, physical education, and active transportation. To the best of our knowledge, this is the first study to estimate combined physical behaviors by considering the combined effect of these four behaviors in 12-15 year-old adolescents in LMICs. Our study provides a comprehensive picture of cross-country differences in physical behaviors in LMICs and can thus help countries formulate intervention programs to keep adolescents physically active.

\section{Limitations}

Our study had the following limitations. First, GSHS is a self-reported survey mainly administered at schools and thus may be susceptible to recall bias. Second, the GSHS was not administered to older adolescents past school age, so the results may not be representative of this group of adolescents. Third, data on specific types of physical activity, frequency, intensity, type, and duration were not collected in the GSHS; thus, metabolic equivalents in adolescents could not be calculated. Fourthly, data on time spent on physical activity during physical education and active transportation were not available. Fifth, we observed high heterogeneity in the meta-analyses when pooling estimates across time and locations. However, heterogeneity can be overestimated when summarizing studies with large sample sizes. In addition, as we analyzed only 12-15 year-old adolescents, the possibility of variation across ages could not be ruled out. Lastly, although we used the latest released data, the data analyzed were at least five years old, and the surveys were conducted between a fairly long period of time (2009-2015).

\section{CONCLUSION}

In conclusion, the prevalence of physical activity, active transportation, and physical education, as well as that of combined physical behaviors, was consistently low among young adolescents in LMICs. Integrated intervention strategies should be advocated to increase physical activity and thereby improve the physical health of adolescents in different countries and regions in accordance with their social, cultural, and economic backgrounds. 


Acknowledgments: We thank the World Health Organization and the Centers for Disease Control and Preven-
tion (CDC) for the data.
Availability of data and materials: The data were obtained from the World Health Organization (WHO) website
(http://www.who.int/ncds/surveillance/gshs/en/), or the Centers for Disease Control and Prevention (CDC) web-
site (https://www.cdc.gov/gshs/index.htm).
Funding: The study is supported by grants from Research Foundation of Hwa Mei Hospital, University of
Chinese Academy of Sciences (2020HMKY35), National Key R\&D Program of China (2017YFC1310902,
2018YFC1315305), Ningbo Health Branding Subject Fund (PPXK2018-02), Sanming Project of Medicine in Shen-
zhen (SZSM201803080), K.C. Wong Magna Fund in Ningbo University.
Authorship contributions: GX, NS, LL, CL, and MZ conceived the study and designed the study in collabora-
tion. LH, ZC and GX analyzed the data and wrote the first draft of the manuscript. All authors interpreted the data
and contributed to subsequent drafts of the manuscript, and all authors have seen and approved the final version.
Conflicts of interest: The authors completed the ICMJE Unified Competing Interest form (available upon request
from the corresponding author), and declare no conflicts of interest.
Additional material
Online Supplementary Document

1 Hallal PC, Andersen LB, Bull FC, Guthold R, Haskell W, Ekelund U, et al. Global physical activity levels: surveillance progress, pitfalls, and prospects. Lancet. 2012;380:247-57. Medline:22818937 doi:10.1016/S0140-6736(12)60646-1

2 Guthold R, Cowan MJ, Autenrieth CS, Kann L, Riley LM. Physical activity and sedentary behavior among schoolchildren: a 34-country comparison. J Pediatr. 2010;157:43-9e1. Medline:20304415 doi:10.1016/j.jpeds.2010.01.019

3 Aguilar-Farias N, Martino-Fuentealba P, Carcamo-Oyarzun J, Cortinez-O'Ryan A, Cristi-Montero C, Von Oetinger A, et al. A regional vision of physical activity, sedentary behaviour and physical education in adolescents from Latin America and the Caribbean: results from 26 countries. Int J Epidemiol. 2018;47:976-86. Medline:29554308 doi:10.1093/ije/dyy033

4 Ortega FB, Ruiz JR, Hurtig-Wennlof A, Sjostrom M. Physically active adolescents are more likely to have a healthier cardiovascular fitness level independently of their adiposity status. The European youth heart study. Rev Esp Cardiol. 2008;61:123-9. Medline:18364180 doi:10.1157/13116199

5 Aljawarneh YM, Wardell DW, Wood GL, Rozmus CL. A Systematic Review of Physical Activity and Exercise on Physiological and Biochemical Outcomes in Children and Adolescents With Type 1 Diabetes. J Nurs Scholarsh. 2019;51:33745. Medline:30895735 doi:10.1111/jnu.12472

6 Friedenreich CM, Neilson HK, Lynch BM. State of the epidemiological evidence on physical activity and cancer prevention. Eur J Cancer. 2010;46:2593-604. Medline:20843488 doi:10.1016/j.ejca.2010.07.028

7 Saunders TJ, Chaput JP, Tremblay MS. Sedentary behaviour as an emerging risk factor for cardiometabolic diseases in children and youth. Can J Diabetes. 2014;38:53-61. Medline:24485214 doi:10.1016/j.jcjd.2013.08.266

8 Hancox RJ, Milne BJ, Poulton R. Association between child and adolescent television viewing and adult health: a longitudinal birth cohort study. Lancet. 2004;364:257-62. Medline:15262103 doi:10.1016/S0140-6736(04)16675-0

9 U.S. Department of Health and Human Services. Physical Activity Guidelines for Americans, 2nd edition, 2018. Available: https://health.gov/paguidelines/second-edition/pdf/Physical_Activity_Guidelines_2nd_edition.pdf. Accessed: 20 March 2019

10 Rendo-Urteaga T, de Moraes AC, Collese TS, Manios Y, Hagstromer M, Sjostrom M, et al. The combined effect of physical activity and sedentary behaviors on a clustered cardio-metabolic risk score: The Helena study. Int J Cardiol. 2015;186:186-95. Medline:25828110 doi:10.1016/j.ijcard.2015.03.176

11 Ekelund U, Steene-Johannessen J, Brown WJ, Fagerland MW, Owen N, Powell KE, et al. Does physical activity attenuate, or even eliminate, the detrimental association of sitting time with mortality? A harmonised meta-analysis of data from more than 1 million men and women. Lancet. 2016;388:1302-10. Medline:27475271 doi:10.1016/S01406736(16)30370-1

12 Landry BW, Driscoll SW. Physical activity in children and adolescents. PM R. 2012;4:826-32. Medline:23174545 doi:10.1016/j.pmrj.2012.09.585

13 World Health Organization. Global Recommendations on Physical Activity for Health. Geneva: World Health Organization, 2010.

14 Barranco-Ruiz Y, Guevara-Paz AX, Ramirez-Velez R, Chillon P, Villa-Gonzalez E. Mode of commuting to school and its association with physical activity and sedentary habits in young Ecuadorian students. Int J Environ Res Public Health. 2018;15:2704. Medline:30513629 doi:10.3390/ijerph15122704

15 Hollis JL, Williams AJ, Sutherland R, Campbell E, Nathan N, Wolfenden L, et al. A systematic review and meta-analysis of moderate-to-vigorous physical activity levels in elementary school physical education lessons. Prev Med. 2016;86:3454. Medline:26592691 doi:10.1016/j.ypmed.2015.11.018

16 Ma C, Bovet P, Yang L, Zhao M, Liang Y, Xi B. Alcohol use among young adolescents in low-income and middle-income countries: a population-based study. Lancet Child Adolesc Health. 2018;2:415-29. Medline:30169283 doi:10.1016/ S2352-4642(18)30112-3 
17 Caleyachetty R, Echouffo-Tcheugui JB, Tait CA, Schilsky S, Forrester T, Kengne AP. Prevalence of behavioural risk factors for cardiovascular disease in adolescents in low-income and middle-income countries: an individual participant data meta-analysis. Lancet Diabetes Endocrinol. 2015;3:535-44. Medline:25957731 doi:10.1016/S2213-8587(15)00076-5

18 World Health Organization. Global School-Based Student Health Survey (GSHS). Available: http://www.who.int/chp/ gshs/en/. Accessed: 26 July 2016.

19 Chandran A, Sousa TR, Guo Y, Bishai D, Pechansky F. Vida No Transito Evaluation T. Road traffic deaths in Brazil: rising trends in pedestrian and motorcycle occupant deaths. Traffic Inj Prev. 2012;13 Suppl 1:11-6. Medline:22414123 doi:1 $0.1080 / 15389588.2011 .633289$

20 Centers for Disease Control and Prevention (CDC). Defining childhood obesity. BMI for children and teens. 2015. Available: http://www.cdc.gov/obesity/childhood/defining.html. Accessed: 29 January 2016.

21 World Health Organization Regional Office for Europe. Inequalities in young people's health. HBSC international report from the 2005/2006 survey. Copenhagen, Denmark: World Health Organization Regional Office for Europe; 2008.

22 Health education and promotion. Available: http://www.emro.who.int/health-education/physical-activity/background. html. Accessed: 24 February 2014.

23 Al-Nuaim AA, Al-Nakeeb Y, Lyons M, Al-Hazzaa HM, Nevill A, Collins P, et al. The Prevalence of Physical Activity and Sedentary Behaviours Relative to Obesity among Adolescents from Al-Ahsa, Saudi Arabia: Rural versus Urban Variations. J Nutr Metab. 2012;2012:417589. Medline:22315673 doi:10.1155/2012/417589

24 Bhowmik J, Biswas RK, Woldegiorgis M. Antenatal care and skilled birth attendance in Bangladesh are influenced by female education and family affordability: BDHS 2014. Public Health. 2019;170:113-21. Medline:30991173 doi:10.1016/j. puhe.2019.02.027

25 Kohl III HW, Cook HD. Educating the student body: taking physical activity and physical education to school. Washington, D. C: National Academies Press, 2013.

26 Smith NJ, Lounsbery MA, McKenzie TL. Physical activity in high school physical education: impact of lesson context and class gender composition. J Phys Act Health. 2014;11:127-35. Medline:23359370 doi:10.1123/jpah.2011-0334

27 Ribeiro EHC, Garcia LMT, Salvador EP, Costa EF, Andrade DR, Latorre M, et al. Assessment of the effectiveness of physical activity interventions in the Brazilian Unified Health System. Rev Saude Publica. 2017;51:56. Medline:28678906 doi:10.1590/s1518-8787.2017051006654

28 Hills AP, Dengel DR, Lubans DR. Supporting public health priorities: recommendations for physical education and physical activity promotion in schools. Prog Cardiovasc Dis. 2015;57:368-74. Medline:25269062 doi:10.1016/j. pcad.2014.09.010

29 UNESCO. World-wide survey of school physical education. Paris: UNESCO, 2014.

30 Dumith SC, Gigante DP, Domingues MR, Kohl HW III. Physical activity change during adolescence: a systematic review and a pooled analysis. Int J Epidemiol. 2011;40:685-98. Medline:21245072 doi:10.1093/ije/dyq272

31 Barr-Anderson DJ, Neumark-Sztainer D, Schmitz KH, Ward DS, Conway TL, Pratt C, et al. But I like PE: factors associated with enjoyment of physical education class in middle school girls. Res Q Exerc Sport. 2008;79:18-27. Medline:18431947 doi:10.1080/02701367.2008.10599456

32 Young D, Saksvig BI, Wu TT, Zook K, Li X, Champaloux S, et al. Multilevel correlates of physical activity for early, mid, and late adolescent girls. J Phys Act Health. 2014;11:950-60. Medline:23676305 doi:10.1123/jpah.2012-0192

33 Badr HE, Lakha SF, Pennefather P. Differences in physical activity, eating habits and risk of obesity among Kuwaiti adolescent boys and girls: a population-based study. Int J Adolesc Med Health. 2017;31:20160138. Medline:28628476 doi:10.1515/ijamh-2016-0138

34 Physical Activity Guidelines for Americans Midcourse Report Subcommittee of the President's Council on Fitness, Sports $\&$ Nutrition. Physical Activity Guidelines for Americans Midcourse Report: Strategies to Increase Physical Activity Among Youth. Washington, DC: US Department of Health and Human Services; 2012. Available: http://health.gov/paguidelines/ midcourse/pag-mid-course-report-final.pdf. Accessed: 16 November 2015. 